\title{
Alegorías de Dulle Griet en el capitalismo tardío. Comentario a la ponencia central de Adela Cortina
}

\section{Dulle Griet's allegories in the late capitalism. Comment to Adela Cortina's central conference}

\section{PhD. Teresa Matus}

La profesora Teresa Matus es doctorada en sociología por IUPERJ en Río de Janeiro y académica de de la Escuela de Trabajo Social de la Universidad Católica de Chile. Avenida Vicuña Mackena 4860, San Joaquín, Santiago,Chile; tmatus@uc.cl

\begin{abstract}
Resumen
Compartiendo ese amplio universo denominado teoria crítica de Frankfurt, se proponen cuatro premisas, a seguir: que la alegoría es un concepto paradojalmente más ajustado y pertinente que la esquizofrenia para evidenciar las ruinas de lo contemporáneo y abrirnos a nuevas visiones; que una segunda noción de sociedad civil en Hegel nos permite asumirla no solamente como fuente del particularismo o un tránsito improbable hacia lo universal sino rescatar su irrenunciable tensión; que los aporoi, los excluidos, son hoy significados en el lugar infernal que hasta el siglo XVI ocupaba Dulle Griet y que si esto se considera, el reconocimiento compasivo universal es una virtud bajo sospecha.
\end{abstract}

Palabras claves: (Teoría crítica - exclusión social - sociedad civil - capitalismo tardio)

\begin{abstract}
Sharing this broad universe called critical theory from Frankfurt, it is proposed four premises: that the allegory is a concept paradoxically closer and proper than schizophrenia to evidence the ruins of the contemporary and to be opened to new visions; that a second notion of civil society in Hegel allows us to assume it not only as a source of special features, or an improbable transit towards universalism, but to rescue its unwavering tension; that the 'aporoi', the excluded, today are meant in that hellish place occupied by Dulles Griet until the sixteenth century, and if it is considered, the universal compassionate recognition is a virtue under suspicion.
\end{abstract}

Key words (Critical theory, social exclusion. civil society, late capitalism) 


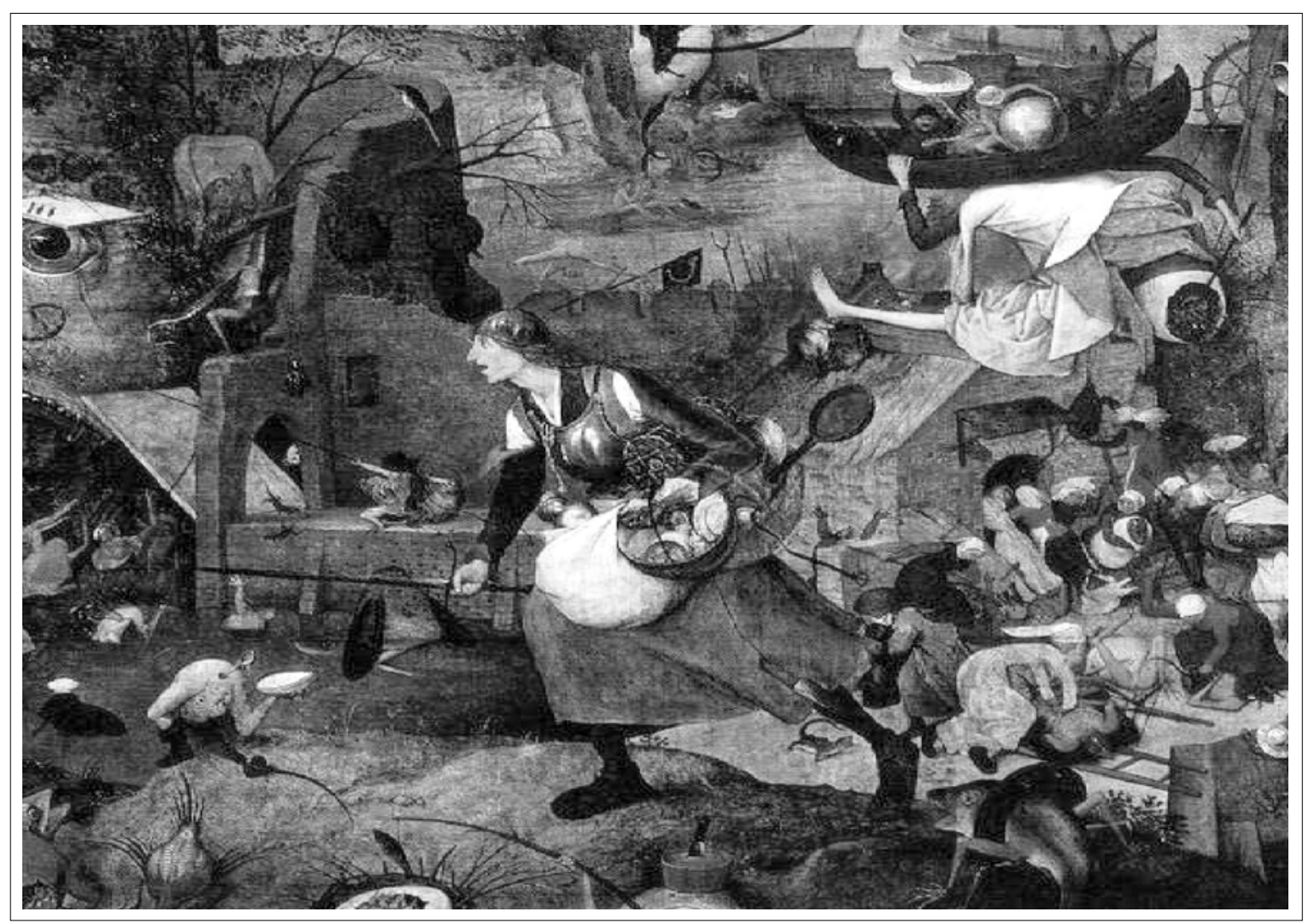

Pieter Bruegel (1525-1569)

\section{lntroducción}

\section{"No podemos olvidar que la esquizofrenia es también el resultado de una tensión mal resuelta" (Theodor Adorno)}

El mundo esquizofrénico que nos presenta Cortina es aparentemente innegable. El que las realizaciones no están a la altura de las declaraciones, nos muestra a las claras las enormes asimetrías de la ciudadanía existentes hoy, donde incluso ese concepto se ha banalizado. La desigualdad se alza como un proyecto donde campea la ética del intercambio infinito. En este panorama, la ética pública asumida desde una perspectiva dialógica nos ofrece una serie de posibilidades para comprender y actuar en el mundo. Precisamente en este terreno es donde el comentario se sitúa, queriendo diferenciar algunas dimensiones, efectuando un cierto ejercicio del matiz. Siguiendo las mismas fuentes y compartiendo ese amplio universo denominado teoría crítica de Frankfurt, se proponen cuatro premisas, a seguir: que la alegoría es un concepto paradojalmente más ajustado y pertinente que la esquizofrenia para evidenciar las ruinas de lo contemporáneo y abrirnos a nuevas visiones; que una segunda noción de sociedad civil en Hegel nos permite asumirla no solamente como fuente del particularismo o un tránsito improbable hacia lo universal sino rescatar su irrenunciable tensión; que los aporoi, los excluidos, son hoy significados en el lugar infernal que hasta el siglo XVI ocupaba Dulle Griet y que si esto se considera, el reconocimiento compasivo universal es una virtud bajo sospecha.

\section{Alegorías}

El recurso a una mirada alegórica abre una suerte de modelo simbólico revelador de una evidencia: la pluralidad de versiones corresponde a una complejidad constituyente del fenómeno. La alegoría en el pensamiento de Benjamín, surge como una forma de crítica capaz de des-hacer la primera apariencia del objeto, destruir su unidad de sentido, presentarla como falsa inmediatez. Alegorizar se presenta aquí como una mirada que hace explotar las significaciones unívocas de los objetos para liberarlos a una pluralidad de sentidos en la que es posible contemplar mejor su complejidad. Así, la alegoría de Benjamin, hace ruinas para iluminar verdades e introducir distinciones. Trabaja, por tanto, a golpes de matiz. 
En el origen del drama barroco alemán, Benjamín procuraba restituir a la alegoría una cierta dignidad epistémica perdida en función de la hegemonía hermenéutica del símbolo ${ }^{1}$. Esta restitución a la alegoría de su carácter expresivo, tiene como telón de fondo la definición clásica y también romántica que reserva para el símbolo la propiedad de revelación de lo momentáneo, lo total, lo necesario y lo insondable cuanto al origen. En este debate están implicadas distintas formas de concepción de la temporalidad y de la historia, temas fundamentales para comprender el pensamiento benjaminiano. En otras palabras, en las concepciones clásicas y románticas el símbolo revela en su inmediaticidad y necesidad de una verdad a-temporal, es decir, una verdad que puede expresarse por la permanencia misma del símbolo en el transcurso del tiempo. De ahí la relación, en estas concepciones, entre verdad y a-historicidad conjugadas en el símbolo. Así, los juicios sobre el valor estético del símbolo y de la alegoría no remiten meramente a una preferencia de gusto, sino que más profundamente, a una apreciación de valor del tiempo y de la historia. Por tanto, la rehabilitación de la alegoría por Benjamín será una rehabilitación de la historia, de la temporalidad y de la muerte en la descripción del lenguaje humano (Gagnebin 1999:41). Es como si una vez muerto el objeto bajo la mirada del alegorista, pudiera surgir la fuente misma de las significaciones pero que ella misma, en tanto fuente, no significara nada².

Sus características antinómicas, son las que pueden hacer convivir las contradicciones y supuestas incoherencias en una misma figura, en este caso la noción de ética pública en una perspectiva dialógica. Alegorizar esta noción, desde otra figura retórica, Dulle Griet, quizás pueda aportar a la desnaturalización de algunos supuestos. En otros términos, este comentario quisiera alegorizar esta noción de ética, haciéndole ruinas en las que otras verdades podrían relevarse, para que se pudiera ver, como decía Benjamín, caminos por doquier. Para ello, se requiere desmontar la interpretación unilateral de la sociedad civil en Hegel, dando paso a una segunda concepción.

\section{El espíritu como fundamento de la sociedad civil}

En Hegel, sus dos discursos acerca de la sociedad civil se fundan y dependen de la forma de interpretación de la idea de Espíritu (Geist): "Son pues, las obras humanas las que dan sentido y vivencia a los conceptos, a las categorías, obras que solamente en este mundo terrenal se pueden construir; se construyen pues históricamente, se expresan en instituciones como el derecho, la familia, la sociedad civil, la policía, la corporación, el estado; en símbolos más altos como el arte, la religión y la filosofía. Todas estas expresiones y símbolos que forman el quehacer humano, forman el Geist, esto es el Espíritu"(Hegel, 1975:36). Éste no es sólo una categoría epistemológica "sino que va más allá del concepto estrictamente de conocimiento para denotar una mayor complejidad. Se adentra en dimensiones distintas y más abarcantes que la razón pura, expandiéndose a la ética, a las instituciones sociales como el Estado y la sociedad civil" (Hernández, 1995:14).

Así, el sistema hegeliano, aparte de su forma, contiene elementos subyacentes que le hacen presentarse como un proceso evolutivo, contradictorio y orgánico. Los tránsitos del Espíritu tienen una finalidad o un fin final, como diría Kant, y éste es justamente la liberación del ser humano. Consecuentemente, el Geist entendido solamente como forma, quedaría reducido a estructura y función, se agotaría en una visión sistémica. Esa visión elimina la posibilidad del mundo de la vida y no sería más que una

1 La noción de crítica en Benjamín se relaciona con sus concepciones del lenguaje, de la modernidad y de redención revolucionaria. Más específicamente, la recuperación de la categoría de alegoría va a desempeñar un papel fundamental en su crítica a la obra de arte en la modernidad como fetiche o, interpretando a Baudelaire, a la pérdida del aura que sufren las obras cuando transformadas en mercancía. Pero, a la diferencia de otros pensadores, Benjamín considera que en esta pérdida reside la posibilidad misma de redención de los objetos. Ver, entre otros: BENJAMIN, Walter. "El país del segundo imperio en Baudelaire"; "Sobre algunos temas en Baudelaire". En: "Poesía y capitalismo - iluminaciones II". Editorial Taurus. Madrid, 1991. BENJAMIN, Walter. "A obra de arte na era da sua reprodutibilidad técnica"; "Teses sobre a filosofia da história; sobre a linguagem em geral e sobre a linguagem humana". En: "Ssobre arte, técnica, linguagem e política”. Relógio d’Água Editores. Lisboa, 1992.

2 "Si el objeto se vuelve alegórico bajo la mirada de la melancolía, ella lo priva de su vida, la cosa yace como si estuviera muerta, pero segura por toda la eternidad, entregada incondicionalmente al alegorista, expuesta a su gracia o a su desgracia. Vale decir, el objeto es incapaz, desde este momento, de tener una significación, de irradiar un sentido; él sólo dispone de la significación que le fue atribuida por el alegorista. Este la coloca dentro de él y llega hasta su fondo; ello no es una realidad psicológica, sino ontológica. En sus manos, la cosa se transforma en algo diferente, a través de ella el alegorista habla algo diferente, ella se convierte en la llave del dominio de un saber oculto y, como emblema de ese saber, él la venera. En eso reside el carácter escritural de la alegoría”. Benjamín(1985:205-206). 
forma descriptiva analítica para explicar fenómenos cibernéticos o bien, fenómenos sociales o políticos (Habermas, 1988:351). El sistema, entendido así, poco tiene que ver con la concepción hegeliana. En ella, es un proceso no sólo de forma sino un corpus cuya posible traducción es el concepto de proceso que evoluciona, se contradice y cambia. Proceso cuyo motor e impulsor es la negatividad y su propia sublimación. El Geist es el mismo proceso que se expresa en la historia y por la vía humana, pero también el Geist es el concepto puro y, sin embargo, histórico.

Por tanto, el Espíritu tiene necesidad de aparecer en el mundo, de resplandecer en las accidentalidades, resquebrajamientos, regresiones y progresiones de la historia. Es allí donde se presenta no como apariencia sino como luminosidad. De esta manera, el sistema hegeliano no puede entenderse sin su cuerpo, sin los accidentes de la historia. Por su propia naturaleza tiene necesidad de aparecer en el mundo. Sin su presencia no habría rememorización. Por tanto, también es un campo de ejercicio y de actores fundamentales cuyo juego es su propia libertad, donde no siempre lo dado muestra su sentido de progresión. Es una cierta actitud de estimar que existen relaciones no visibles que hay que descubrir ${ }^{3}$. Así, el Geist requiere de lo finito sin perder su infinitud.

Hegel sostendrá que: "La conservación de un pueblo o un estado, de las esferas ordenadas de su vida, es un momento crucial en el curso de la historia. Y las actividades de los individuos consisten en tomar parte en la obra en común. Pero el otro momento reside en que el Geist de un pueblo vea quebrantada su consistencia por haber llegado a su agotamiento. De esta destrucción, justamente, surgen las grandes colisiones entre los deberes, las leyes, los derechos existentes, y ciertas posibilidades que son opuestas a este sistema. Estas posibilidades se hacen, empero, históricas, ya que encierran un contenido universal de distinta especie que se constituye en la base de la existencia de un pueblo" (Hegel, 1987: 91). Por encima de un pueblo, por tanto, existe una actitud histórica universal de un ideal más justo. La colisión de deberes que engendra la desobediencia civil se da en esta zona de grandes perturbaciones, el fin final, como dice Kant, es la libertad plena y en el sentido de Hegel, el desenvolvimiento de la idea que se hace terrena en la conducta de determina- dos hombres. Estas son las bases, los fundamentos del espíritu que posibilita entender, en Hegel, sus dos discursos de la sociedad civil: La sociedad civil en la filosofía del derecho representa a la sociedad burguesa y su sistema de racionalidad. Por tanto, su discurso legal está traspasado de razón funcionalista. Sin embargo, hay otra noción de sociedad civil que funda su discurso en la razón cultural, en el espíritu absoluto.

Esta dualidad discursiva, institucional y comunicativa, son expresiones dialécticas del Geist, pero ellas no tienen ni la misma jerarquía ni el mismo valor. "Lo que comienza por ser subjetivo se hace sustancial en su relación frente al otro, sin esa relación, la conciencia permanece encerrada en sí, en el terreno de la buena voluntad" (Hernández, 1995:42). Para Hegel, la apertura de la conciencia va a permitir la evolución del hombre, el paso del espíritu subjetivo al espíritu objetivo. Esto es válido para el primer discurso. Pero en el segundo, el espíritu se vuelve espíritu absoluto. En este último discurso, la sociedad civil tendrá dos frentes: "uno, la sociedad global y el otro, el Estado. El sistema de poder político va a polemizar con todo el poder sistémico" (Bobbio, 1990: 89). En este nivel, es posible generar un vínculo comunicativo. Aunque en su división y apariencia la sociedad civil sea espíritu objetivo, ésta también puede emerger como espíritu absoluto, como razón comunicativa (Hernández, Op. Cit. p. 45). En el primer discurso, la proliferación de familias genera la sociedad civil por un fenómeno económico y de división del trabajo, su intercambio, la lucha por los bienes. Esta actitud egoísta que cancela al otro y lo ve como medio, no como fin, se expresa en un sistema jurídico que sirve para proteger los bienes y la seguridad de esta sociedad. Luego, acá la sociedad civil es un atomismo social en donde a cada hombre no le interesan sino sus deseos particulares, por tanto, no es posible la perspectiva de la universalidad.

De esta manera, la sociedad civil en tanto razón instrumental es histórica, contradictoria y presenta "un espectáculo de miseria y corrupción"(Hegel, 1987: 78). Hegel va a denominar a toda esta estructura: el sistema de necesidades. La razón es contingente y su sentido es la satisfacción de necesidades básicas. Por ello, la sociedad civil encierra tres momentos:

i La mediación necesaria y de satisfacción con el trabajo. Este es el sistema de necesidades.

3 De algún modo su logos, el Geisha que permea al mundo es una aventura, al igual que en Kano. KANT, Emmanuel. "Filosofía de la historia". Editorial Fondo de Cultura Económica. México, 1987. Pág. 95 a 118. 
ii La realidad de lo universal contenida en el sistema de justicia.

iii La prevención contra la accidentalidad que subsiste en este sistema y el cuidado por los bienes particulares en cuanto cosa común.

Es una sociedad civil, en palabras de Marcuse: "fundada en bases de una razón distorsionada por la ciega necesidad del progreso económico y una libertad pervertida por la competencia de intereses privados en conflicto" (Marcuse, 1986: 211). Esa sociedad civil no procura la igualdad sino que produce desigualdad ${ }^{4}$. En dicha noción, no se habla del deber ser sino del ser. Por otra parte, la sociedad civil no puede impedir el exceso de pobreza porque ella es una consecuencia natural de la sociedad civil ya que al fincar la libertad en la propiedad, la sociedad civil se transforma en ley, "en el absoluto derecho de apropiación del hombre sobre las cosas"(Hernández, 1995: 78). La pobreza, por tanto, no se resolverá por lo jurídico porque forma parte de las estructuras del sistema mismo. Es decir, la sociedad civil actúa dentro de la estructura del Estado. La cosa pública es, de este modo, un polo atractivo de la particularidad. "Lo particular y lo universal se imbrican. Lo interesante no es un mayor poder del Estado sino que la sociedad civil misma tiene ya potencialmente la tendencia de pasar de su esfera a la dimensión estatal y no obstante continuar la función dual como los estamentos" (Hegel, Op. Cit. p. 150). De lo anterior se desprende que el Espíritu objetivo es una totalidad compleja, pero en ella la diferencia entre sociedad civil y Estado es clara. Es la distancia entre individuos y un objetivo superior. "Como la sociedad civil es el campo de batalla de todos, el conflicto de negocios particulares, contra los más elevados puntos de vista del Estado "(Ibíd.: 189). El Estado es así el Espíritu objetivo por excelencia, donde la libertad abraza la plenitud de sus derechos. Sin embargo, Hegel destaca la variable cultural pero ya no en el Espíritu objetivo sino en el Espíritu Absoluto. "Ya no se da en el sistema de necesidades de la sociedad civil ni en el Estado sino que las rebasa en un discurso comunicativo" (Hernández, Op. Cit. p. 80).

Luego, dicho Geist, sin cancelar sublima las instituciones y se expande en una esfera más elevada y enriquecida por el objeto: el Espíritu Absoluto. Acá la sociedad civil ya no es el sistema de necesidades, ni el sistema sociológico (Estado), ni el sistema jurídico (Ley); sino que ésta en el segundo discurso se constituye por otras variables: estética, cultural, ética. El discurso primero de las necesidades es demasiado poderoso para que la sociedad civil pueda ser en él una instancia comunicativa. El segundo discurso, en cambio, se vuelve crítico, polémico y friccionador (Foucault, 1979:157). Aquí, la sociedad civil es el género humano, la humanidad como tal que se concreta en lo finito, o sea históricamente. Es por esta razón que si bien esto en Hegel es un círculo, ello no es un obstáculo para mostrar las dos tendencias de la sociedad civil. Visto de este modo, en Hegel, sobre la sociedad civil individualista y competitiva, sobre esa sociedad funcional, existe el Estado y sobre éste, otra sociedad civil que aparece como racional. "El discurso de esta sociedad no es un discurso que expresa fenómenos económicos sino comunicativos con expresiones diversas de aquél, en la perspectiva del arte y la cultura" (Hernández, Op. Cit. p. 84). Esta segunda sociedad civil, concebida como horizonte, inmersa en un campo universal, racional y ético, se inserta en un discurso cultural que es el propio de los valores elevados que dice de lo bello, de lo santo y de lo conceptual.

Por tanto, en el primer discurso, "en los Estados de la época moderna, la seguridad de la propiedad es el pivote de toda legislación y al que se refiere la mayor parte de los derechos ciudadanos" (Hegel, 1984: 175). Esto es un discurso que contiene una racionalidad funcional, instrumental, técnica. El segundo discurso, en cambio, es ético y comunicativo. Es ético, porque está construido para el encuentro racional con otro, único capaz de hablar de lo bello, lo santo y lo conceptual. La liberación del hombre permea el segundo discurso. Se trata de un discurso crítico, que devela lo que no se ajusta a lo dado, que penetra en la superficie para descubrir otra realidad más verdadera, aprehendiéndola. Por ello es que tanto el Estado como los dos conceptos de la sociedad civil pueden ser mirados dialécticamente.

\section{Dulle Griet en el cielo del capitalismo tardío}

Lo anterior tiene una importancia vital. Si bien podemos reclamar de la primera interpretación hegeliana de la sociedad no podemos desecharla sin más, sino tensarla con la segunda. Si en vez de esto, transfor-

4 Como sostendrá Know, "a la diversa naturaleza Egea la acepta, pero a ella agrega la construida por la riqueza y el poder. El sistema de necesidades es un proceso, por su propia estructura es una totalidad orgánica de diferenciación”. Hernández, Raúl. "La Idea de Sociedad Civi 
mamos la sociedad civil en otra cosa, puede incluso ser vista como un polo de reivindicación de las tareas que el Estado ya no asume, donde mediante la filantropía se ensancha un camino a mayores causes de solidaridad y desarrollo. ¿Cuál es el problema de esta visión? : el olvido de Dulle Griet.

Si tomamos las fuentes de información más diversas, en todas nos encontramos con tendencias que muestran un crecimiento indiscutido en relación con la sociedad civil y el servicio cívico: en los últimos diez años, ha existido un promedio de crecimiento del $16 \%$ de asociatividad según el índice CIVICUS, realizado en 86 países, lo que involucra altas tasas de participación El crecimiento de las organizaciones sin fines de lucro, ha sido constante en las últimas dos décadas, llegando a crecimientos de hasta 38\% en algunos países. El voluntariado como porcentaje del empleo total de las organizaciones sin fines de lucro varía entre países: en las zonas en desarrollo alcanza un $0,7 \%$ y en los países más desarrollados un 2,6\%. Según Anheier, el empleo total de las OSFL como porcentaje de la población económicamente activa en una muestra de 36 países es la siguiente: las OSFL dan empleo alrededor del 4,8\% de la población económicamente activa y generan 2,6\% de voluntariado, destacándose países como Holanda donde el sector sin fines de lucro da empleo al 9,2\% de la población.

Por otra parte, en relación con el nuevo modelo de negocios que plantea la Responsabilidad Social Empresarial, hoy no sólo existen más empresas que adhieren al modelo, sino que hay diversos centros internacionales de estudios y mediciones que producen, entre otros, ranking internacionales de responsabilidad social empresarial, evaluados en tres grandes áreas: desempeño ambiental, económico y social. En resumen, tenemos que en el mundo hoy existe: más asociatividad, más organizaciones sin fines de lucro, más voluntariado, más empleos generados por la Sociedad Civil, más empresas con sistemas de Responsabilidad Social Empresarial, más Servicio Cívico a nivel internacional. ¿Será entonces el tiempo de la sociedad civil? ¿Habremos pasado de una sociedad Estado céntrica a una mercado céntrica para derivar en una socio céntrica? ¿Por qué, entonces, con un panorama de estas características es oportuno pensar en paradojas?

Charles Tilly, en su texto sobre la desigualdad (Tilly, 1998), nos llama la atención acerca de cómo se distribuye y cuáles son sus efectos, cómo se manifiesta en una política y de qué forma se perpetúan ciertas lógicas que contribuyen a un cuadro de desigualdad persistente, entre hombre/mujer, aristócrata/plebeyo, ciudadano/extranjero. En este punto se cruza con las investigaciones de Amartya Sen (Sen, 1981, 1982, 1983, 1992) el que a partir de sus análisis de pobreza y hambruna ha descubierto un tratamiento deliberadamente desigual en presencia de recursos que podrían asegurar un bienestar más general. Si el ejemplo extremo lo constituye el infanticidio femenino, práctica ancestral no sólo en Asia y África si tomamos en cuenta la investigaciones de John Boswell en "La misericordia ajena" (Boswell, 1999) también podríamos colocar una larga lista donde no faltarían: limitación exclusivamente masculina a cierta educación, desvío de reservas alimentarias, aislamiento, donaciones de tercera clase, privilegios, deferencia, aprovechamiento en nombre de la solidaridad, filantropía del espectáculo, seguridad del marketing. Aún más, se habla de una desterritorialización del Tercer Mundo para indicar justamente que ese movimiento contradictorio se encuentra en medio de ciudades que atraviesan los continentes, donde se ven surgir zonas de miseria locales en las que los indicadores básicos de calidad de vida experimentan un retroceso sustantivo que da como resultado una equiparación con los índices de las denominadas naciones tercermundistas.

Sin embargo, esta situación social degradada, reconocida ampliamente por diversos autores y estudios, contrasta con un capitalismo regenerado que no hace sino crecer y dar lucro. Hoy las multinacionales controlan $2 / 3$ del comercio internacional, del que aproximadamente la mitad está constituida por exportaciones intergrupales, de casa matriz y filiales extendidas por el mundo. Su participación en los gastos de investigación y desarrollo es aún más importante, llegando a financiar más de $1 / 3$ de las pesquisas, sobre todo en áreas tecnológicas, farmacéuticas e incluso de estudios sociales (Chesnais, 2004). Ahora bien, ¿cuál es la relación de este escenario, con las organizaciones de la sociedad civil y el servicio cívico? Voy a plantear una hipótesis provocadora: Ya en los planteamientos clásicos de Marx, el capitalismo conllevaba un espíritu de revolución constante e imparable (Marx,1972) y Weber diagnosticaba en profundidad la transformación del capitalismo a comienzos del siglo XX. El capitalismo, por tanto, desde su gestación requirió de un espíritu, de una forma de legitimación que pudiera apoyar su propia expansión. Ahora bien, si este espíritu en su movimiento inicial, estaba constituido por la ética protestante, planteo que el nuevo espíritu del capitalismo está configurado por la filantropía. 
Que la filantropía en todas sus formas, responsabilidad social empresarial, financiamiento de organizaciones sociales, respaldo de investigaciones, responde incluso a sistemas que contemplan la crítica al modelo global. ¿Cómo puede ser posible lo anterior? Porque, entre otros factores, estamos ante un giro cultural sin precedentes. En la edad media la avaricia era condenada no sólo por la Iglesia con la excomunión, sino que se representaba la figura del avaro como alguien que no cesaba en sus intentos de acumulación, donde el rico era condenado a los infiernos y el dinero se asimilaba al mal. De hecho los pobres nos recordaban el camino recto y seguro hacia el cielo, lo que lleva al propio San Francisco a hacer de la pobreza una forma de vida. Hoy, el retorno al integrismo del dinero, a la orquestación de la desigualdad en la dialéctica de la modernización, ha tomado otros caminos. No sólo el dinero resulta perdonado, sino que sus operadores ganan el éxito simbólico. Ya no son los pillos de Stendhal, o los nuevos ricos de Balzac. Adiós a los cuentos de Dickens, donde el rico moría sólo y contando sus monedas mientras al pueblo le pertenecía la fiesta. Ya no tenemos a Dulle Griet, aquel avaro rico que pinta Bruegel, como alguien tan absurdo que ni en el infierno suelta su bolsa de monedas. En la alegoría de una pirueta invertida, Griet hoy alcanza el cielo.

Así nos podemos explicar que actualmente las empresas sean los modelos filantrópicos en este nuevo espíritu y existan ranking de competición empresarial de solidaridad. Sólo que no podemos olvidar, como ya nos decía Shakespeare: "son los mismos, Iago, son los mismos, en sus fantasmas". Son los mismos cinco gobiernos que más consumen energía (Estados Unidos con un 38\%, Canadá, Alemania, Japón y Francia, con otro 30\% en conjunto), los que financian formas de ahorro de consumo energético y los que regulan las condiciones de operación en países del tercer mundo. Algunas de las mismas empresas internacionales que compiten por los ranking de solidaridad, son las que aumentan sus ganancias y además, como Mc Donald generan problemas serios en la nutrición de la población, o en el caso de algunas industrias químicas o farmaceúticas son las que, a la vez, experimentan "nuevos productos" en África o en Asia.

Encandilados con lo que Eliana Vejar llama "la cultura del espectáculo" (Véjar, 2004) ya no reconocemos detrás de tanta filantropía, el antiguo oficio del cambista. Sólo que a diferencia del siglo XVI éste ya no cuenta las monedas en la intimidad de su casa, a solas con su mujer, sino que lo hace en me- dio de todas las luces de los foros públicos, siendo admirado, reconocido y envidiado, como forma de vida plena. Por esto, no podemos soslayar a Dulle Griet. Esa verdad, todavía posible en el siglo XVI, se encuentra hoy altamente contrastada. Nos hace violencia incluso su imagen. Tan naturalizado tenemos hoy el capital, que él se ha transvestido y nos mira desde la gloria. De allí que incluso esta alegoría nos resulte claramente ofensiva. En ella podemos experimentar su desplazamiento. Griet se vuelve hoy un ícono admistiado. Pero no sólo eso, en la medida que el adinerado resulta admistiado, es la figura misma del pobre, entendida ahora como perdedor, como ganador del vacío, la que esta ideología convoca al tribunal de la modernidad. Hasta el siglo XIX la figura del burgués, estaba marcada por un signo negativo que Francois Furet pone claramente de relieve: es el pillo de Stendhal, el filisteo en Marx. El rebajamiento estético del avaro es notable: mezquino, feo, tacaño, laborioso, casero. El dinero y la avaricia endurece el espíritu y lo rebaja.

La franja transitiva del cambista, donde ya el oficio de prestar dinero, condenado al infierno por todo el pensamiento escolástico, especialmente en Santo Tomás, se ha esfumado. Su argumento era clarísimo: nadie puede beneficiarse haciendo préstamos, ya que allí se especula con algo que no nos pertenece, ya que todo el tiempo pertenece a Dios. Esta noción ha sido infiltrada, se ha ido minando y volviendo ruina desde una creación: la invención del purgatorio (Jacques le Goff, 1998) Hoy, ese infierno ha desaparecido sin dejar huellas. Nadie reconoce más el carácter infernal de Dulle Griet. Incluso transitivamente si el burgués detentaba el poder, al menos debía defender la ilegitimidad moral de su estatuto. Si el dinero tenía el poderío al menos todavía no tenía la gloria. Hemos roto ahora con esa regulación simbólica. He aquí una nueva configuración: Dulle Griet no sólo gobierna sino que también reina y nos contempla, enviándonos nuevas promesas salvíficas, dando aportes incluso a los excluidos. Es un Griet en la cúspide celestial.

Claramente, con el modelo de orden (y ayer Ze Paulo, nos colocaba esto como tarea al plantear que el orden contemporáneo es el desafío central), es que cada sociedad moldea a sus pobres a su propia imagen, explica su presencia en forma diferente y les da una diferente función, adoptando estrategias distintas (Bauman, 2001). Pero no se trata de retornar al Bosco. De persistir en visiones lineales. De marcar ascensos y descensos, de imágenes en un solo sentido. A veces esta tentación no sólo ha estado presente 
en algunos dictadores (como Franco en El Escorial) sino se ha tornado una atracción mucho más popular y al alcance de un precio más módico. Se trata entonces, de componer una alegoría compleja mostrando sus matices, no sólo en relación a Griet sino a los pobres frente a él. La Europa premoderna estuvo más cerca que su sucesora en el intento de hallar una función importante para los pobres. Estos, al igual que todas las personas y las cosas en esa Europa, cristiana y premoderna, eran hijos de Dios y constituían un eslabón indispensable en la divina cadena del ser, como parte de la creación divina y como el resto del mundo antes de su desacralización por la moderna sociedad racionalista, estaban, por así decirlo saturados de significado y propósito divinos. Sufrían, es cierto, pero su dolor encarnaba el arrepentimiento colectivo. Incluso quedaba en manos de los más afortunados socorrer y aliviar a quienes sufrían y de este modo, practicar la piedad y obtener ellos también una parte de su salvación. Los pobres eran y en muchos lugares no han dejado de serlo, de una manera espectral, la oportunidad para vivir una vida virtuosa. Se podría decir que una sociedad que buscara el sentido de la vida en la vida después de la muerte habría necesitado de otro camino, de no contar con los pobres, para la salvación personal de los más acomodados. Así, los propios pobres, por su función social, tenían una tremenda promesa como horizonte: tener el cielo garantizado. Pero en cuanto los pobres dejan entrever que se entretienen, que les gusta la fiesta, en cuanto aparece la figura del pícaro (como en el lazarillo de Tormes o en algunos cuadros de Velásquez) allí la noción de merecimiento se rebaja. Lo que vende es la miseria yaciente, no la ciudadanía. Como quieran llamarlo, La miseria del mundo (Bourdieu, 1992), La banalidad del mundo (Arendt, 1985), Cuando el mundo se ha vuelto miseria (Horkheimer, 1937). Esa paradoja extrema sigue siendo nuestra agenda.

Es en este marco crítico del ideario normativo de la modernidad, que tanto Habermas como Apel, ponen un énfasis insoslayable en la autonomía constituida intersubjetivamente como presupuesto para la construcción normativa de la sociedad. Así, en la propuesta de la ética discursiva, la autonomía constituida intersubjetivamente se revela como fundamento antropológico de un horizonte ético/normativo comprometido con la justicia social y compatible con los desarrollos de las sociedades pluralistas y democráticas contemporáneas (Habermas, 1999). Se trata entonces, de configurar una intervención, que mediante sus postulados éticos y sus formas de operacionalización pueda poner al propio capitalismo en una encrucijada, a lo menos, siendo obligado a "ver".

\section{La compasión universal bajo sospecha}

Lo anterior es extraordinariamente relevante ante el auge de la compasión como espectáculo (Arteta, 1996), aquél sufrimiento a distancia como denomina Boltansky al humanitarismo mediático (Boltansky, 1993), directamente aquél mal samaritano como lo llamará Helena Béjar (2001). Donde uno da y el otro, agradecido, recibe. Insistiendo en esta asimetría desde otra perspectiva, siempre se desconfiará de la bondad plena de un acto si el agente se detiene a contemplarlo y a gozarse de él; si lo anuncia y lo va proclamando como bueno. Dará motivos para sospechar que detrás de lo proclamado trabaja y bulle un mecanismo de autojustificación. "Hablar es un evento, algo que ocurre en un tiempo y en un espacio determinados y que, en virtud de su sentido, produce diversos tipos de efectos en el espacio civil. Esto es, justamente, un "evento de sentido" Ricoeur, 1998:43). Este es el argumento conductor de Hannah Arendt que va de la caritas a la vida activa y a la ciudadanía. No es la emergencia, por tanto, de un ámbito público lleno de publicidad que enfatiza la solidaridad compasiva a tal punto que la trivializa, sino la emergencia de una acción humana recíproca y constituyente $e^{5}$

Esto es importante de destacar en un tiempo donde paradojalmente crecen dos representaciones sociales, dos imaginarios constituidos tanto por un énfasis en el requerimiento solidario de la ayuda como por una transformación de una exaltación de la riqueza y un rechazo a toda la ambigüedad casi sacra que la pobreza tuvo en otras épocas: "mientras el rico se veía ennoblecido por el espíritu del tiempo presente, el pobre descendía hacia los infiernos de la relegación simbólica. La cuasi-desaparición de una contracultura obrera, el hundimiento del sindicalismo, la eliminación de los cuerpos intermedios o asociativos, favorecen este progresivo retroceso social. Por lo demás, el pobre a menudo agrava su situación votando mal, es decir, por la derecha. Simbólicamente, cambia de estatuto: ya

5 "Ela chegou a compreender os 'tempos sombrios' modernos como tempos em que o âmbito público se atrofiou e a publicidade, longe de embelezar os empreendimentos humanos, os trivializa" Young-Bruehl, Elizabeth. "Hannah Arendt - Por amor ao mundo". Editora Relumé Dumará. Río de Janeiro, 1997. Pág. 434. 
no es el 'trabajador', el 'obrero' o el 'camarada'. Se convierte en el 'medio pelo', el jugador de apuesta triple, el caddy, el botones sobrecargado o el campesino gruñón. ¿Pero deja por eso de ser él mismo? La pregunta no se formulará. En el Hemisferio Sur, el 'condenado de la tierra' líricamente valorado en los años sesenta sufre la misma descalificación. Ya no es sino la partícula infinitesimal de una masa oscurantista, exiliada en el pensamiento mágico, un terrorista en potencia, un inmigrante virtual o, peor aún, un integrista. El investigador Olivier Roy, especialista en el Islam, demostró con claridad cómo había resultado fracturada la solidaridad natural entre intelectuales occidentales y militantes del Tercer Mundo después de la confesionalización de estos últimos" (Guillebaud, 1995: 45) Ante esos avances no sólo de desigualdades en términos económicos, sino en el enfrentamiento de esos imaginarios sociales: "¿Es posible que nos quedemos fríos como el mármol? ¿Se pretenderá que esos asaltos virtuales de la desdicha permanezcan sin ecos? ¿Cerraremos los ojos? ¿Nos plantaremos, impávidos, en el 'chauvinismo del bienestar'? ¿Deberemos reaprender poco a poco la ignorancia voluntaria o, peor aún, 'acostumbrarnos'? La pregunta es absurda. 'El sufrimiento obliga' (Ibíd:58).

Pongamos, en fin, una última cuestión -recurrente -en las ostentaciones mediáticas que propagan de otra manera la retórica victimaria. Notamos a simple vista que obedecen a esta alquimia que permite aislar en la complejidad de lo real una sola molécula químicamente pura: el desamparo ${ }^{6}$. La intención es amable, pero la víctima es un plano cerrado, la imaginería humanitaria literalmente la separa de lo real. Ignora todo el resto, el contexto, los complementos, los agregados que son mantenidos fuera de campo. Al hacerlo, rompe todo vínculo entre la víctima y su propia pertenencia, su dignidad. Arrancada de sí misma, por lo demás, la mayoría de las veces se muestra a la 'presa' humanitaria acostada, yacente, sumisa. Ya no tiene ni lenguaje ni rostro. Es un mero pretexto para la aflicción, el desamparo lamentable e incluso infrahumano. "Es objeto de piedad y no sujeto de derechos. ¡Qué diferente de esas multitudes perseguidas pero de pie y que proclaman su ira! Esta imaginería victimaria es sulpiciana. Es una impostura benévola, pero impostura al fin" (Ibíd: 69). "El humanitarismo -exclamaba Stephen Smith al volver de Ruanda- es la amnesia del presente, el impulso de esa limosna antigua, el gesto que salva, el pensamiento que se abisma en el océano tibio de los buenos sentimientos. Ayudo, luego soy humano"(Smith., 1995:70). En efecto, "iqué estatuto acordar a esta salmodia perezosa que machaca con las mismas conmiseraciones, que gasta las mismas metáforas simplonas -'las imágenes insostenibles', 'el infierno en Somalia', 'el horror en Goma' "la infra-vida en el tercer mundo"-, sino el de una lengua estereotipada y vacía, que verdaderamente un día habrá que descodificar y criticar con un poco de seriedad?".(Guillebaud, Op. Cit. p. 70)

En el borde de esa idea ronda un tipo de frialdad, de pragmatismo decadente, de econometría metafísica, donde a falta de utopías verdaderas, el mundo se transforma en un espectáculo lleno de cifras. Lo más terrible de esa posibilidad es que ella sería posible en un tipo de sociedad donde los hombres han dejado de ejercer la humanidad y han olvidado ese principio ejemplar que Bloch llamada esperanza (Bloch, 2005). En esas circunstancias y en forma invertida, por exceso y trivialización, por tener los ojos llenos de media, de reality show, de necesidad de apariciones públicas, se nos aparece como un espectro temible el personaje desencantado que hace surgir la Beauvoir en todos los hombres son mortales: "me dirigí hacia la puerta; yo no podía arriesgar mi vida, yo no podía sonreírles, nunca había lágrimas en mis ojos ni llamas en mi corazón. Sólo cálculo, economía y cifras. Un hombre de ninguna parte, sin pasado, sin futuro, sin presente. Yo no quería nada; no era nadie. Avanzaba paso a paso hacia el horizonte que retrocedía a cada paso que daba; las gotas de agua brotaban, caían; el instante destruía el instante; mis manos estaban vacías para siempre. Un extraño, un muerto. Ellos eran hombres, ellos vivían. Yo no era uno de ellos. Yo no tenía nada que esperar" (Beauvoir, 1983: 379).

En el Trabajo Social esperamos, mediante una pasión emancipatoria que ha formado parte de sus riquezas y que constituye un horizonte permanente de discernimiento y creatividad para la intervención social, ya que "no hay posiciones privilegiadas fuera o por encima de la historia desde las que contemplar la vida humana. Y no hay cosas tales como la interpretación correcta: 'Cada época habrá de comprender [...] a su manera [...]. Se comprende de otra manera si se comprende de nuevo' (Gadamer, 1992:140)". De allí que el requerimiento de una comprensión compleja es uno de los fundamentos insustituibles de todo proyecto de intervención

6 Aunque no es el objetivo del trabajo, es interesante connotar aqui el auge de las nociones de vulnerabilidad, de fragilidad, de riesgo. 
social. Ahora bien, en esos mecanismos de comprensión compleja, fundamentales para el ejercicio de trabajar lo social, es donde se requiere de la búsqueda de una potenciación ciudadana en tanto no se puede pasar por alto a las propias personas que van a ser objeto de un programa o de una política social ${ }^{7}$. Sobretodo, es dable recordar aquí que, la articulación de la necesidad en el discurso práctico utilizará los estándares de valor existentes; en tanto son interpretadas, las necesidades están internamente ligadas a valores culturales y, por tanto, son inseparables de ellos" (McCarthy, 1992:194). Además, esta relación debe considerar que históricamente no importa lo que pase en el futuro: el bien supremo de la paz universal es inalcanzable, ya que las incontables víctimas de la historia nunca podrán participar de él. Están muertas y desaparecidas. Su sufrimiento es irremediable. "Así pues, el imperativo de la razón de buscar la justicia perfecta debe ser, por utilizar los términos de Kant, 'fantástica', debe estar dirigido a 'fines imaginarios', o ser, en expresión de Peukert, 'una pesadilla' (Peukert, 1992:225-26). Una tradición de saber como el Trabajo Social, que recogiera justamente aquellas experiencias, no sólo en un registro de lo escrito, sino en las ancestrales y renovadas formas de la oralidad, de los silencios, de lo que nunca fue visto, de lo que no aparece en la escena pública mediática, podría contribuir a dar forma a un ejercicio de ciudadanía más plena.

Un Trabajo Social que reflexione sobre "esa sombra en la idea de una justicia adquirida al precio de la irremediable injusticia perpetrada sobre las generaciones anteriores. Esta sombra no puede ser borrada; como mucho se la puede olvidar. Pero este olvido dejará tras de sí los vestigios[...]. Aquellos nacidos después sólo pueden resarcir la contradicción contenida en la idea de justicia completa, complementando el pensamiento abstracto de la universalidad con el poder anamnésico del recuerdo que va más allá de los conceptos de la moralidad misma. Este recordar se actualiza en la conmoción con aquellos que han sufrido y sufren hasta el punto que ya no podrá volverse a hacerles bien" (Habermas, 1992: 226). Un Trabajo Social que adquiera desde esas entrañas con-movidas por el dolor y la indignación, la escritura de un amor al mundo que recoja las formas múltiples de la polifonía, valdría la pena de ser re-creado, refundado e inventado con toda la fuerza de la pasión de un oficio. Pero ello, involucra recordar. Si Adorno nos recuerda que el mayor poder de la dominación es el olvido, no podemos entonces, en nuestras luchas, olvidar esta historia alegórica de Dulle Griet en el capitalismo tardío.

\section{Bibliografía}

ARTETA, AURELIO (1996) La compasión. Apología de una virtud bajo sospecha. Editorial Paidós, Barcelona.

BEAUVOIR, SIMONE DE (1983). Todos Los Hombres Son Mortales. Eitorial Bruguera. Barcelona.

BEJAR, HELENA. (2001) El Mal Samaritano. El Altruismo en Tiempos de Escepticismo. Ediciones Anagrama. Barcelona.

BENJAMIN, WALTER (1991). El País del Segundo Imperio. En Baudelaire (1991) "Poesía Y Capitalismo - Iluminaciones II". Editorial Taurus. Madrid, 1991.

BENJAMIN, WALTER (1992) A obra de arte na era da sua reprodutibilidad técnica; Teses sobre a filosofia da história; sobre a linguagem em geral e sobre a linguagem humana". En Sobre arte, técnica, linguagem e política Relógio d'Água Editores. Lisboa, 1992.

BAUMAN, ZYGMUNT. (2001) La posmodernidad y sus descontentos. Madrid: Akal.

BLOCH, ERNST. El Principio Esperanza. Editorial Trotta. Madrid, 2004.

BOBBIO, NORBERTO (1990) Por una Teoría General de la Política. Editorial Alianza. Madrid.

BOLTANSKY, JEAN LUC (1993) La Soufrance a Distance. Moral Humanitaire, Médias Et Politique. Editions Métailié. París.

FOUCAULT, MICHEL (1979) Microfisica del Poder. Editorial La Piqueta. Barcelona, 1979.

GADAMER, H. G. (1992) Verdad y Método. Editorial Tecnos. Madrid, 1992.

GAGNEBIN, JEAN MARIE (1999) Historia y Narración en Walter Benjamín, Editora Voces. Sao Paulo.

GUILLEBAUD, JEAN-CLAUDE (1995). La Traición de la Ilustración. Ediciones Manantial. Buenos Aires.

GUILLEBAUD, JEAN-CLAUDE (1995). La devoración de las víctimas. Ediciones Manantial. Buenos Aires.

HABERMAS, JÜRGEN (1988). La Lógica de las Ciencias Sociales. Editorial Tecnos. Madrid, 1988.

\footnotetext{
7 "Nadie puede construir una identidad al margen de las identificaciones que los demás hacen de él [...]. [El ego] se muestra a sí mismo como un ego práctico en la realización de acciones comunicativas; y en la acción comunicativa los participantes deben presuponer recíprocamente que el distinguirse-de-lo-otros es reconocido por esos otros. De este modo la base para la afirmación de la propia identidad no es realmente la autoidentificación, sino la autoidentificación reconocida intersubjetivamente Habermas, Jurgen. (1998:158).
} 
HABERMAS, JURGEN (1992) Habermas: Critical Debates Citado en: Mccarthy, Thomas. "Ideales e Ilusiones - Reconstrucción y Deconstrucción en La Teoría Crítica Contemporánea". Editorial Tecnos. Madrid.

HABERMAS, JURGEN. (1998) Comunicación y la Evolución de la Sociedad. Editorial Tecnos. Madrid.

HEGEL, G.W. (1975) Filosofía del Derecho. Editorial Sudamericana. Buenos Aires.

HEGEL, G.W.F. (1987). Filosofía de la Historia. Editorial Alianza. Madrid.

HERNÁNDEZ, RAÚL (1995) La idea de Sociedad Civil en Hegel. Ediciones UNAM. Serie de estudios doctrinales $\mathrm{N}^{\mathrm{o}}$ 169.Instituto de Investigaciones Jurídicas. México.

KANT, EMMANUEL (1987) Filosofía de La Historia. Editorial Fondo de Cultura Económica. México.

MARCUSE, HERBERT (1986) Razón y Revolución. Editorial Alianza. Madrid.
MATUS, TERESA (2001) Hacia una Intervención Polifónica: Propuestas Contemporáneas en Trabajo Social. Editorial Espacio, Buenos Aires.

MCCARTHY, THOMAS (1992) Ideales e Ilusiones Reconstrucción y Reconstrucción en la Teoría Crítica Contemporánea. Editorial Tecnos. Madrid.

PEUKERT, (1992) Science, Action and Fundamental Theology. Citado en: Mccarthy, Thomas. "Ideales e Ilusiones - Reconstrucción y Deconstrucción en la Teoría Crítica Contemporánea". Editorial Tecnos. Madrid.

RICOEUR, PAUL (1998) Texto, Totalidad e Infinito. Ediciones Anagrama. Barcelona.

SMITH, STEPHEN (1992). Liberation. Ediciones Manantial. Buenos Aires, Técnica, Linguagem E Política". Relógio D’água Editores. Lisboa, 1992.

YOUNG-BRUEHL, ELIZABETH. (1997) Hannah Arendt - por amor ao mundo. Editora Relumé Dumará. Río de Janeiro. 